\title{
MALDI-TOF MS - application in food microbiology
}

\author{
Monika Akimowicz ${ }^{\bowtie}$ and Joanna Bucka-Kolendo \\ Department of Microbiology, Prof. Wacław Dąbrowski Institute of Agriculture and Food Biotechnology, Warsaw, Poland
}

Microbiological purity control of food products is of great importance in the food industry. Contaminated food is often characterized by a deteriorated taste, smell, and appearance, and when consumed, it can pose a threat to human health and life. Also, contamination incurs huge financial losses to the food industry. Different methods are used for identification of the microorganisms isolated from food, which are based on phenotypic, immunologic, genetic, and spectroscopic techniques. Unfortunately, these methods have the following disadvantages: laborious, time-consuming, requiring a well-trained spectrometer operator with specialist knowledge, or very accurate, but complicated, and extremely expensive. In recent years, matrix-assisted laser desorption/ionization-time of flight mass spectrometry (MALDI-TOF MS) has been gaining increasing importance in the field of food microbiology. Unlike other techniques used for microorganisms identification, MALDI-TOF MS is more rapid, accurate and cost-efficient, and easy to perform. Thus, this method can be applied in the food industry to quickly and accurately identify microorganisms, which is crucial for controlling the quality of food products. The present review aims to discuss the selected applications of MALDI-TOF MS in food microbiology. It mainly focuses on the characteristics of this method and its potential use in the identification and typing of microorganisms including filamentous fungi, yeasts, and bacteria in fermented beverages (beer and wine), honey, dairy products like yogurt and pasteurized milk, pork, and seafood.

Key words: food quality and safety, MALDI-TOF MS, identification of microorganisms, filamentous fungi, yeasts, bacteria

Received: 05 June, 2020; revised: 27 July, 2020; accepted: 28 August, 2020; available on-line: 14 September, 2020

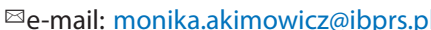

Abbreviations: API, analytical profile index; DGGE, denaturing gradient gel electrophoresis; LAB, lactic acid bacteria; MALDI-TOF MS, matrix-assisted laser desorption/ionization-time of flight mass spectrometry; PCR, polymerase chain reaction; $\mathrm{qPCR}$, quantitative polymerase chain reaction; ZEA, zearalenone

\section{INTRODUCTION}

Microbiological safety is of fundamental importance in the quality control of products in the food industry (Nicolaou et al., 2012). Food-spoiling microorganisms produce metabolites that change the sensory properties of products, such as appearance, texture, taste, and smell, as well as reduce their nutritional value (Böhme et al., 2012; Nicolaou et al., 2012). This also incurs huge economic losses to the food industry. Food-spoilage bacteria do not usually cause illness in humans, however, ingesting them in high amounts may cause gastrointestinal disturbances. Described spoilage bacteria include, among others, Pseudomonas putida, Pseudomonas fragi, Erwinia spp., Photobacterium spp. and Shewanella spp. (Böhme et al., 2012). Also, food poisoning is a very serious threat to human health and life, especially for young and elderly people. Food intoxications are the result of the consumption of food containing toxins produced by bacteria during growth and multiplication as a by-product. Unfortunately, pathogenic microorganisms (which constitute a group of microorganisms other than food-spoilage microorganisms) are difficult to recognize in contaminated products as they often do not alter their sensory properties (Böhme et al., 2012; Nicolaou et al., 2012). The most common pathogens causing food spoilage are, among others, Listeria monocytogenes, Escherichia coli O157:H7, Campylobacter jejuni, Salmonella enterica, Clostridium perfringens, Staphylococcus aureus, Leuconostoc mesenteroides, and Bacillus cereus (Böhme et al., 2012; Elbehiry et al., 2017).

Analysis of the microbiological purity of food products involves the detection, identification, and determination of the number of microorganisms, including food-spoilage bacteria, food-borne pathogens, probiotics and starter cultures (Nicolaou et al., 2012; Pavlovic et al., 2013). Traditional methods that are used for the identification of microorganisms isolated from food are based on phenotypic techniques, such as observing the morphology and growth of microbes on the media, Gram staining of the cells, performing catalase and oxidase tests, analyzing gas production from glucose, microscopically evaluating the cell morphology and type of hemolysis, and conducting biochemical assays, such as tests for indole, urease, or aminopeptidase (Böhme et al., 2012; Soro-Yao et al., 2014; Lévesque et al., 2015). However, these methods are time-consuming and laborious, and also require a spectrometer operator for correct interpretation of the results (Moothoo-Padayachie et al., 2013; Lévesque et al., 2015; Nomura, 2015). In addition, immunologic (antibody-based assays), such as enzyme-linked immunosorbent assay (ELISA), and molecular methods together with bioinformatic tools, such as polymerase chain reaction (PCR), repetitive sequence-based polymerase chain reaction (rep-PCR), randomly amplified polymorphic DNA-polymerase chain reaction (RAPD-PCR), DNA fingerprinting techniques, intron splice site primers, sequencing of the $16 \mathrm{~S}$ rRNA gene, PCR in combination with sequencing, real-time PCR (quantitative PCR, qPCR), micro-satellites, DNA microarrays, mitochondrial DNA restriction fragment length polymorphism (RFLP) analysis, restriction enzyme analysis (REA), restriction enzyme analysis with pulsed-field gel electrophoresis (REA-PFGE), simple sequence repeats (SSR), denaturing gradient gel electrophoresis (DGGE), PCRDGGE fingerprinting, temporal temperature gradient gel electrophoresis (TTGE), PCR-temperature gradient gel electrophoresis (PCR-TGGE), internal transcribed spacer (ITS)-PCR, multilocus sequence analysis (MLSA), 
and biosensors, as well as spectroscopic methods, such as Fourier-transform infrared spectroscopy (FT-IR) and pyrolysis-mass spectrometry (PyMS) are used for the identification of microorganisms (Böhme et al., 2012; Moothoo-Padayachie et al., 2013; Quintela-Baluja et al., 2013; Soro-Yao et al., 2014). Although these methods allow effective identification, most of them are complicated, laborious, time-consuming, and expensive to use. This makes routine analysis using the techniques mentioned difficult to perform (Moothoo-Padayachie et al., 2013; Quintela-Baluja et al., 2013; Soro-Yao et al., 2014; Nomura, 2015). Therefore, there is a search for new microorganism identification methods that are fast, accurate, reliable, highly specific, uniform for the analysis of various groups of microorganisms, cost-efficient, and easy to perform. Proteomic methods seem to be promising in this respect (Böhme et al., 2012; Quintela-Baluja et al., 2013; Lévesque et al., 2015; Nomura, 2015).

\section{PROTEOMICS}

Proteomics is a dynamically developing, relatively new study field that deals with the composition, structure, and function of proteins, as well as the relationship between the proteins present in the cells, tissues, and the entire organisms. The set of proteins present in a cell, encoded by the genome, is called the proteome. Proteomics is applied for the detection of biomarkers (can be single proteins or entire changed protein profiles), which allows the identification of cells and microorganisms (Szczepańska \& Robak, 2013).

The most important techniques used in the proteomic analysis are two-dimensional electrophoresis, electrospray ionization (ESI), and matrix-assisted laser desorption/ ionization-time of flight (MALDI-TOF) (Szczepańska \& Robak, 2013).

\section{CHARACTERISTICS OF MALDI-TOF MS TECHNIQUE}

For more than 10 years, MALDI-TOF has been used for the routine identification and typing of Gram-positive and Gram-negative bacteria, mycobacteria, actinomycetes, yeasts, and mold fungi (Pavlovic et al., 2013; Lévesque et al., 2015; Quéro et al., 2018; Pomastowski et al., 2019). Also, this technique was applied to analyze phyloproteomic relationships (Böhme et al., 2012a). Recent studies showed that MALDI-TOF is also suitable for the quantification of proteins (Welker \& Moore, 2011; Nicolaou et al., 2012). Moreover, MALDI-TOF mass spectrometry (MS) can be used for the detection of other biomolecules, such as sugars, nucleic acids, and small molecules (Pavlovic et al., 2013).

\section{MALDI-TOF MS TECHNIQUE}

MALDI-TOF MS, a chemotaxonomic technique, involves the analysis of ribosomal proteins that are characteristic for a given family, genus, species, or even a microorganism strain. To perform this analysis, first, a small amount of test material $\left(10^{5}-10^{6}\right.$ cells; intact cells or cell extracts) is transferred to a plate. Next, a matrix solution containing $\alpha$-cyano-4-hydroxy-cinnamic acid, 2,5-dihydroxy-benzoic acid, or 3,5-dimethoxy-4-hydroxycinnamic acid (sinapinic acid, SA) in a mixture of solvents: water, $2.5 \%$ trifluoroacetic acid (TFA), and 50\% acetonitrile (ACN), ethanol or methanol is applied to the sample. These matrix components penetrate the mi- crobial cells and extract out the intracellular proteins, thereby making them available for the analysis. After evaporation of the solvents from the cell suspension, matrix crystals containing protein molecules and other cellular compounds are formed (co-crystallization process). In the next stage, the dried sample is placed in the analyzer chamber, where desorption (release) and ionization of matrix molecules and proteins (without degradation) of the microorganism take place under the influence of a laser. Due to its ability to strongly absorb the energy of the laser light, the matrix plays an important role in the desorption and ionization process, leading to the release of analyte molecules. The resulting ionized molecules are accelerated in a vacuum analyzer column and the time of ion flight (TOF) is measured. Initially, lowmass ions reach the detector, followed by the high-mass ionized charged molecules. Then, the MALDI-TOF MS system automatically generates (based on the distribution of peptides according to their molecular weight, charge, and ion flight time) a peak spectrum (mass spectrum) in which the peaks correspond to ions with different massto-charge ratios $(\mathrm{m} / \mathrm{z})$. The mass spectra obtained are characteristic for a particular species of microorganism (so-called fingerprint). The MALDI-TOF MS system also allows analyzing the peak intensity, quantity, and peak correlation, and comparing the mass spectra of a given living organism with the spectra in the existing mass spectral database (Welker \& Moore, 2011; Pavlovic et al., 2013; Kosikowska et al., 2015; Singhal et al., 2015; Cieślik \& Wróblewska, 2018). By comparing the ion biomarker masses of an unknown microorganism with the protein masses in the database or by comparing the whole-protein profile with a library consisting of the mass spectra of the reference strains (fingerprint approach, a designation of the number of peaks that are characteristic of the genus and/or species of microorganisms), it is possible to identify microorganisms at the level of genus, species, and even strain (Böhme et al., 2011; Böhme et al., 2012). The general principle of the MALDI-TOF MS technique was presented in Figure 1.

\section{ADVANTAGES AND DISADVANTAGES OF MALDI-TOF MS}

The application of the MALDI-TOF MS technique in microbiological diagnostics is gaining increasing attention. Some advantages of the technique are its simplicity, very high sensitivity, accuracy, and reproducibility. Also, it allows a much shorter confirmation time for species identification (10 $\mathrm{min} / \mathrm{sample})$ compared to biochemical tests, involves minimal sample preparation, and requires only a small amount of sample for analysis (one colony, $10^{5}$ cells) (Böhme et al., 2011; Böhme et al., 2012; Böhme et al., 2012a; Vranakis et al., 2012; Kosikowska et al., 2015; Brodzik et al., 2016; Cieślik \& Wróblewska, 2018). Furthermore, the method is much cheaper than the conventional and biochemical assays used for microorganisms identification, such as analytical profile index (API), polymerase chain reaction (PCR), real-time PCR, and genome sequence analysis (Böhme et al., 2011; Böhme et al., 2012; Böhme et al., 2012a). The average cost taken by the API tests for microbial identification at the species level is 15 euros/sample, while MS costs only 0.15 euro/sample (Vranakis et al., 2012). Importantly, MALDI-TOF allows analyzing a complex protein mixture, while achieving over $92 \%$ correct identification of the microbial species (Böhme et al., 2011; Böhme et al., 2012; Böhme et al., 2012a; Quintela-Baluja et al., 2013). Addi- 


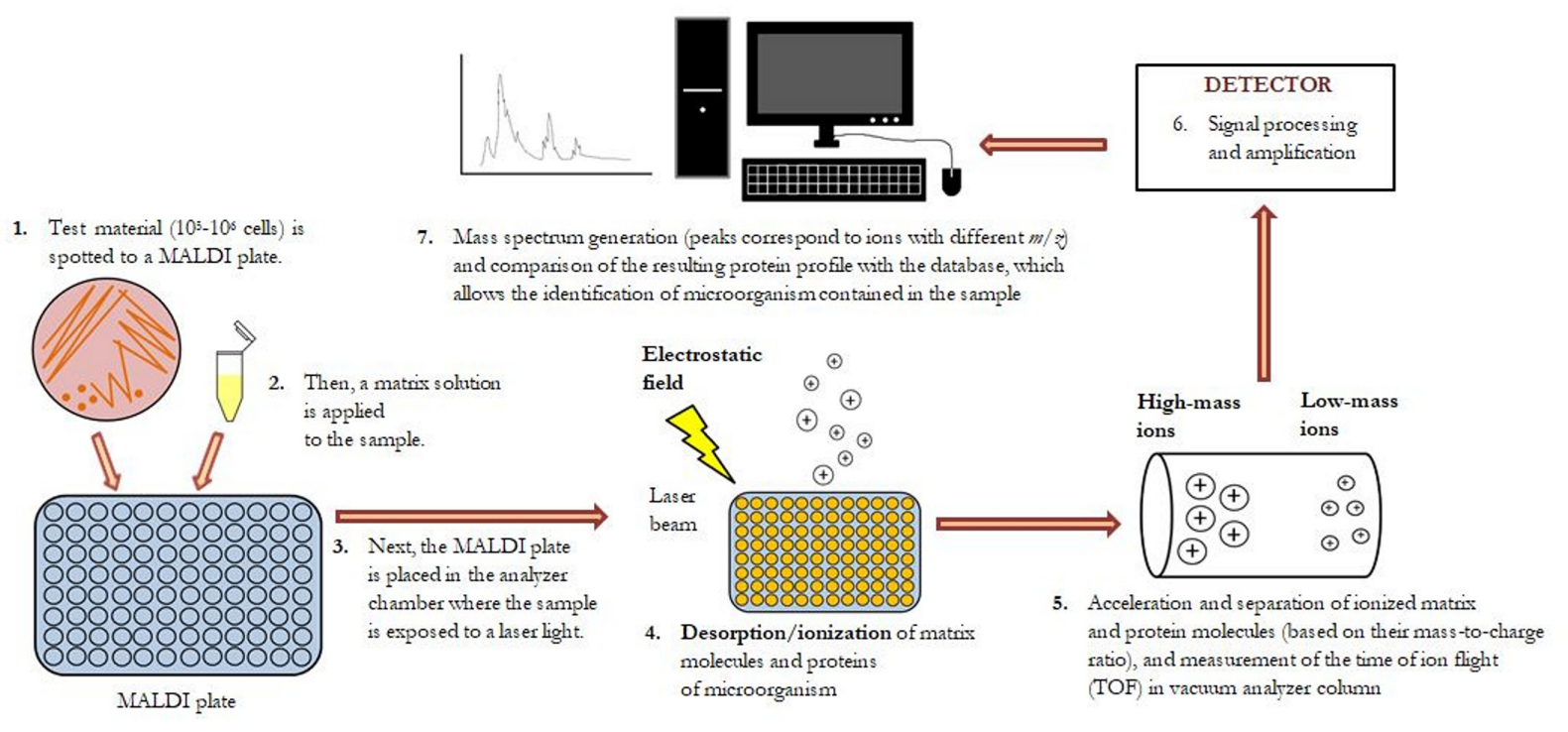

Figure 1. Scheme showing the general principle of the MALDI-TOF MS analysis of a sample (developed based on Clark et al., 2013; Ouedraogo et al., 2013; Singhal et al., 2015; Lo et al., 2017; Mazari et al., 2017)

tionally, the method enables the identification of rarely isolated microorganisms based on their protein profile. This is possible thanks to the existence of a very large database that is constantly updated and expanded. Currently, the database contains protein profiles of several thousand recognized and confirmed species of microorganisms from around the world. Another advantage of the MS technique is that it does not require an initial diagnosis for the identification of microorganisms (Kosikowska et al., 2015). The available scope of the microbial database (reference spectra database) determines the reliability of MALDI-TOF MS (Brodzik et al., 2016).

However, the method has the following limitations: difficulty in identifying microorganisms having high phylogenetic relatedness, lack of protein profile of some species in the database, and the possibility of technical errors, for example when the sample is applied to the plate for analysis (Cieślik \& Wróblewska, 2018). Moreover, the cost of the MALDI-TOF MS system is also very high. However, the low price of the reagents and reduced labor costs, in the long run, compensate for the equipment cost (Elbehiry et al., 2017).

The following section provides an overview of the MALDI-TOF MS applications in food microbiology for the identification and typing of filamentous fungi, yeasts, and bacteria.

\section{IDENTIFICATION AND TYPING OF MICROORGANISMS ISOLATED FROM FOOD}

Although filamentous fungi (e.g. Penicillium spp., Fusarium spp., and Aspergillus spp.) have many beneficial characteristics such as the ability to produce organic acids, enzymes, and antibiotics and can be used for the production of fermented foods, they produce mycotoxins and contaminate many food products. It is estimated that fungal spoilage accounts for $5-10 \%$ of the food loss worldwide. Quéro and others (Quéro et al., 2018) used the MALDI-TOF MS technique to quickly identify the food-spoilage molds. They created a database based on the mass spectra of 618 fungal strains belonging to 136 species obtained by MS. The database allowed about $95 \%$ correct identification of fungi at the species level, regardless of the incubation time followed and culture medium applied (evaluation based on cross-validation) (Quéro et al., 2018).

Saccharomyces cerevisiae strains play a very important role not only in brewing, wine-making, and baking but also in the pharmaceutical and nutraceutical industries. Also, these microorganisms produce L-lactic acid and some secondary metabolites. Moothoo-Padayachie et al. proved that the MALDI-TOF MS technique is a much better biotyping tool for the identification of industrial yeast strains than molecular methods such as PCR amplification using delta elements and contour-clamped homogenous electric field gel electrophoresis (CHEF). The MS method allowed 100\% correct identification of $S$. cerevisiae at the genus and species level and about $90 \%$ correct identification at the strain level (18 out of 20 tested strains). The investigators indicated that two samples containing misidentified yeasts at the strain level were contaminated. Molecular methods failed to correctly distinguish all the $S$. cerevisiae strains tested. However, the MALDI-TOF MS method, applied with multivariate statistics and principal component analysis, allowed a clear distinction between brewing yeast strains $\mathrm{SAB} \mathrm{MC} \mathrm{CO}$ and $\mathrm{SAB} \mathrm{MC}$ UF. The authors concluded that the MALDI-TOF MS technique can therefore be used in the industry for quality control of starter cultures and detecting contamination (Moothoo-Padayachie et al., 2013).

Fermented beverages such as beer, wine, or cider, as well as starter cultures as mentioned above, can be contaminated by "wild yeast" which results in spoilage of the final product. Such spoiled products have an unpleasant aftertaste (e.g. phenolic), appear turbid, and contain less ethanol. Usbeck and others (Usbeck et al., 2013) proved that the MALDI-TOF MS method is a fast and reliable technique for identifying fermented beverage-spoiling yeast species such as $S$. cerevisiae var. diastaticus, Wickerhamomyces anomalus, and Debaryomyces hansenii. However, the authors pointed out that the method is limited by the availability of reference spectra in the database. Also, they suggested that ethanol can be used for extraction, as this solvent allows obtaining spectra with the highest and reproducible number of peaks. Moreover, their study 
showed that factors such as cell density, growth phase, oxygen availability, and various nutrients can cause some minor changes in the mass spectra of microorganisms (Usbeck et al., 2013).

Certain bacteria also have the ability to spoil beer. Therefore, the differentiation and classification of such microorganisms are extremely important in the brewing industry. Kern and others (Kern et al., 2014) evaluated the beer-spoiling ability of Lactobacillus brevis strains isolated from wheat, lager, and pilsner beer, as well as their tolerance to iso-alpha acids which have antibacterial properties. Additionally, they identified these strains using the MALDI-TOF MS technique. The tested bacteria showed different levels of beer-spoiling ability (low/ moderate/high). The higher the resistance to iso-alpha acids, the higher the bacteria ability to spoil beer. The authors also noted that the resistance of bacterial isolates to iso-alpha acids depended on many factors, including the presence or absence of ethanol or nutrients. The MALDI-TOF method allowed 90\% correct identification of beer spoilage microorganisms at the strain level (Kern et al., 2014).

In an unfavorable environment, many forms of lactic acid bacteria (LAB) can enter into VBNC - a viable but nonculturable state (Bucka-Kolendo et al., 2017), where they still remain viable and can be a threat to the food safety. In this state, bacteria cannot be identified with classical microbiology methods, however, identification based on peptide markers may be useful in this case (Calo-Mata et al., 2016).

The presence of mycotoxins such as zearalenone (ZEA) in food products is a serious threat to human health. Król and others (Król et al., 2018) used the MALDI-TOF technique to analyze the ability of LAB to neutralize ZEA produced by the fungi of Fusarium genus, such as Fusarium graminearum, Fusarium cerealis or Fusarium culmorum. Based on changes in the mass spectra (appearance or disappearance of signals as a function of time) after the incubation of bacteria with ZEA for 0 (control), 10, and $20 \mathrm{~min}$, the researchers confirmed the uptake of mycotoxin by Lactococcus lactis and Bifidobacterium sp. bacteria. The extent of neutralization and binding of ZEA by Gram-positive bacteria corresponded to the amount of teichoic acids, polysaccharides, proteins, and peptidoglycan in their cell wall (Król et al., 2018).

Pomastowski and others (Pomastowski et al., 2019) identified the microorganisms present in different types of honey, of various geographical and botanical origins (e.g. buckwheat, multiflower, honeydew, sunflower, forest), using MALDI-TOF MS and 16S rDNA. Both research techniques resulted in the identification of Bacillus spp., Brevibacillus spp., Staphylococcus spp., Micrococcus spp., and Lysinibacillus spp. However, in contrast to the $16 \mathrm{~S}$ rDNA technique, the MALDI-TOF method enabled a clear distinction between species such as Bacillus subtilis and $B$. cereus. This finding is of research importance because these two species are the most common microbes found in honey (Pomastowski et al., 2019). At the same time, Böhme et al. examined the Gram-positive strains belonging to Listeria spp., Staphylococcus spp., Bacillus spp., Clostridium spp., and Carnobacterium spp., which were isolated from contaminated seafood, using the MALDI-TOF method. They detected genus-specific and species-specific mass peaks that can be used as biomarkers for the identification of the studied bacteria. Also, the authors conducted a phylogenetic analysis of the tested strains based on the 16S rRNA gene. In their studies, the MALDI-TOF technique permitted to identify the microorganisms much more accurately when compared to the 16S rRNA gene analysis. An unambiguous distinction of Bacillus licheniformis, Bacillus amyloliquefaciens, and B. subtilis by phylogenetic analysis was considered difficult due to the high similarity of their DNA sequence. However, MS made it possible to distinguish the $B$. licheniformis strain from the other strains belonging to the Bacillus genus through different protein profiles characteristic for a given strain. Therefore, the authors concluded that the MALDI-TOF technique can be used for the routine identification of food-borne pathogens such as $S$. aureus, B. cereus, L. monocytogenes, and Clostridium botulinum, as well as for the identification of bacteria exhibiting less pathogenic activity and nonpathogenic ones (Böhme et al., 2011).

Contamination of food (e.g. rice, pasta, herbs, milk, and dairy products) by the heat-stable cyclic depsipeptide cereulide produced by some strains belonging to $B$. cereus species causes emetic food poisoning in humans. Urlich et al. used the MALDI-TOF technique as well as the PCR method and bioassays (HEp-2 cytotoxicity test) to identify the emetic and nonemetic bacterial strains. The MS method allowed 99.1\% correct distinguishing of strains with or without the ability to produce emetic toxin (120 out of 121 tested strains/isolates). Only one emetic strain producing an extremely small amount of toxin was inappropriately identified. It was observed that all emetic strains had two specific biomarkers $(\mathrm{m} / \mathrm{z} 171$ and $1187 \mathrm{Da}$ ) in the mass spectrum (Urlich et al., 2019).

Nicolaou et al. used the MALDI-TOF method in conjunction with chemometric analysis to identify and quantify the bacteria contaminating pasteurized milk and pork. Their study showed that the mass spectra of fresh and spoiled milk and pork varied slightly. Food-spoiling bacteria metabolized the proteins or peptides contained in the food products, resulting in the formation of new peptides or proteins. This caused changes in the intensity and area of the peaks in the mass spectrum and even led to the disappearance of certain peaks. The investigators also performed linear and nonlinear regression analyses to quantify the number of bacteria. They proposed that the MALDI-TOF MS technique in combination with chemometry can be used in the dairy and meat industries for the detection and quantification of bacteria (Nicolaou et al., 2012).

Fermented food with probiotics has a positive effect on the digestive, respiratory, and immune system of humans. The probiotic strains that are most commonly used in dairy products include LAB, such as Lactobacillus casei, Lactobacillus acidophilus, and Bifidobacterium spp., as well as bacteria of the Enterococcus, Streptococcus, and Pediococcus genera. Angelakis et al. used MALDI-TOF MS and molecular assays (PCR amplification and sequencing of tuf and $16 \mathrm{~S}$ rDNA genes) to identify the bacteria present in probiotics and yogurt. They found Lactobacillus delbrueckii and Streptococcus thermophilus in yogurt, Lactobacillus delbrueckii in probiotic yogurt, and Lactococcus lactis, Lactobacillus casei, and Bifidobacterium animalis in probiotic drinks. The results showed that the MALDI-TOF technique allowed better identification of bacterial strains in the tested food products ( $92 \%$ correct identification), compared to the qPCR method (Angelakis et al., 2011). However, some studies showed (Bucka-Kolendo et al., 2020) that treating lactic acid bacteria with stress factor, like high hydrostatic pressure (HHP), can affect the identification of microorganisms, if the identification technique is based on the protein profile. The data obtained from the protein mass fingerprinting analysis of some lactobacilli strains showed differences in unpressured and pressured 
mass spectrum profiles (MSPs), which influenced the results of the identification.

Enterococcus bacteria are very commonly isolated from food products and are often used as starter cultures. However, two species of this genus, namely Enterococcus faecalis and Enterococcus faecium, which produce biogenic amines and virulence factors, cause infections in humans that can be a threat to their health and life. For this reason, the identification of these bacteria isolated from food is important. Quintela-Baluja et al. characterized 36 strains of different species belonging to the Enterococcus genus using MALDI-TOF MS. Based on the presence or absence of certain peaks in the mass spectrum and differences in the mass peaks, they distinguished individual species and even some strains of the same species. Their study showed that the biomarker of the Enterococcus genus is a peak at $m / z 426 \pm 1$. The authors also found that the origin of the strain (dairy or meat products) affected the occurrence of mass spectra (biomarkers) with different $m / z$ values and, while also determining the frequency of some peaks in the mass spectrum (Quintela-Baluja et al., 2013).

Fernández-No et al. also confirmed that the MALDITOF technique is suitable for the rapid identification of enteric and marine bacteria producing histamine. Consumption of fish or seafood, cheese, wine, and other food products containing bacteria that are capable of performing histidine decarboxylase activity, such as Staphylococcus xylosus, Klebsiella pneumoniae, Proteus vulgaris, Lactobacillus sp. 30A, or Photobacterium phosphoreum, leads to histamine poisoning. The mass spectra of the bacterial strains analyzed in the study allowed their clear distinction. Similar protein profiles (peak intensities and their number) were obtained for all biogenic amines-producing species of the Enterobacteriaceae family. Based on the differences in peak masses, the authors distinguished the bacteria at the species level (Fernández-No et al., 2010).

Bacteria of the Cronobacter genus are opportunistic food-borne pathogens and cause serious neonatal infections. These microorganisms are phenotypically similar to the nonpathogenic bacterial species such as Enterobacter helveticus, Enterobacter turicensis, and Enterobacter pulveris. However, Stephan et al. correctly identified all Cronobacter strains at the genus and species level using the MALDI-TOF MS technique (Stephan et al., 2010).

According to the literature reports, the $16 \mathrm{~S}$ rRNA gene sequencing has some limitations concerning the identification of closely related LAB at the species and subspecies level. To this end, it is necessary to use other methods, such as MALDI-TOF MS or perform sequencing of protein-coding genes. Sánchez-Juanes et al. used the MALDI-TOF MS and phes gene analysis to identify LAB in "Torta"-type cheese. The MS analysis showed that the species isolated from the cheese samples were Lactobacillus paracasei, Lactobacillus rhamnosus, Lactobacillus plantarum, Lactobacillus diolivorans, Lactobacillus curvatus, Lactococcus lactis, and Leuconostoc mesenteroides. The analysis of partial sequences of $p h e S$ gene confirmed the genus- and species-level identification of the bacteria shown by the MALDI-TOF MS technique. Also, the MALDI-TOF MS method together with pheS gene analysis enabled identifying some isolated strains at the subspecies level (Sánchez-Juanes et al., 2020).

Some species of Weissella genus are used in fermented foods as probiotics. However, species such as Weissella confusa cause serious infections in humans (e.g. sepsis). Identification of $W$. confusa using conventional biochemical methods and commercial automated systems is difficult because it is often confused with microorganisms belonging to the Leuconostoc and Lactobacillus genera (Fairfax et al., 2014; Lee et al., 2015). Fairfax et al. reported that only the $16 \mathrm{~S}$ rDNA sequencing method and the MALDI-TOF MS technique helped in the correct identification of $W$. confusa in blood samples of the patients (Fairfax et al., 2014).

\section{CONCLUSIONS}

The microbiological safety of food depends on the amount and type of microorganisms present or the number of toxins produced by them. The presence of some microorganisms in food may be beneficial because they can carry out the fermentation process (e.g. lactic acid or alcoholic fermentation), improve the quality and nutritional value of the food products, biosynthesize food ingredients, and produce preservatives and biomass. On the other hand, the presence of some microbes results in spoilage, deteriorates quality, and reduces the nutritional value of food, as well as causes food poisoning in humans after consumption of the product (KołożynKrajewska, 1995).

The present review showed that MALDI-TOF MS is a simple, very accurate, fast, and cost-efficient technique. It is a more powerful discriminating tool than other molecular methods such as $16 \mathrm{~S}$ rDNA sequencing. MALDI-TOF MS allows almost faultless identification of microorganisms at the genus and species level while achieving about $90 \%$ correct typing of microbial strains. For this reason, it is increasingly used in the food industry for the routine identification and typing of microorganisms, such as filamentous fungi, yeasts, and bacteria which are isolated from food. Thus, MALDI-TOF MS can be successfully used to identify microbes and detect their metabolites in various types of food products, such as beer, wine, cider, honey, pasta, rice, herbs, milk, and dairy products, pork, and fish or other seafood. Expanding the existing databases with more species and strains of microorganisms will allow identification of a much broader group of microorganisms, including those present in food, in the future.

\section{REFERENCES}

Angelakis E, Million M, Henry M, Raoult D (2011) Rapid and accurate bacterial identification in probiotics and yoghurts by MALDI-TOF Mass Spectrometry. J Food Sci 76: M568-M572. https://doi.org/ 10.1111/j.1750-3841.2011.02369.x

Böhme K, Fernández-No IC, Barros-Velázquez J, Gallardo JM, Cañas B, Calo-Mata P (2011) Rapid species identification of seafood spoilage and pathogenic Gram-positive bacteria by MALDI-TOF mass fingerprinting. Electrophoresis 32: 2951-2965. https://doi. org/10.1002/elps.201100217

Böhme K, Fernández-No IC, Barros-Velázquez J, Gallardo JM, Cañas B, Calo-Mata P (2012) Species identification of food spoilage and pathogenic bacteria by MALDI-TOF mass fingerprinting. Food Quality, Kostas Kapiris, IntechOpen. https://doi.org/10.5772/33884

Böhme K, Fernández-No IC, Barros-Velázquez J, Gallardo JM, Cañas B, Calo-Mata P (2012a) SpectraBank: An open access tool for rapid microbial identification by MALDI-TOF MS fingerprinting. Electrophoresis 33: 2138-2142. https://doi.org/10.1002/elps.201200074

Brodzik K, Augustynowicz E, Korzeniowska-Kowal A, Lutyńska A (2016) Application of the MALDI-TOF for identification of Clostridium perfringens strains. Med Dośw Mikrobiol 1: 13-21 (in Polish)

Bucka-Kolendo J, Sokołowska B (2017) Lactic acid bacteria stress response to preservation processes in the beverages and juice industry. Acta Biochim Pol 64: 459-464. https://doi.org/10.18388/ abp.2017_1496

Bucka-Kolendo J, Sokołowska B, Winiarczyk S (2020) Influence of high hydrostatic pressure on the identification of Lactobacillus by MALDI-TOF MS-preliminary study. Microorganisms 8: 813. https:// doi.org/10.3390/microorganisms8060813

Calo-Mata P, Böhme K, Carrera M, Caamaño-Antelo S, Gallardo JM, Barros-Velázquez J, Cañas B (2016) Bacterial identification by LC- 
ESI-IT-MS/MS In Microbes in the spotlight: recent progress in the understanding of beneficial and harmful microorganisms. Méndez-Vilas A ed, pp 160-164. Publisher: BrownWalker Press, Universal Publishers Inc., Boca Raton, FL, USA

Cieślik J, Wróblewska M (2018) MALDI TOF MS - new possibilities in routine microbiological diagnostics. Diagn Lab 54: 99-104 (in Polish)

Clark AE, Kaleta EJ, Arora A, Wolk DM (2013) Matrix-assisted laser desorption ionization-time of flight mass spectrometry: a fundamental shift in the routine practice of clinical microbiology. Clin Microbiol Rev 26: 547-603. https://doi.org/10.1128/CMR.00072-12

Elbehiry A, Marzouk E, Hamada M, Al-Dubaib M, Alyamani E, Moussa IM, AlRowaidhan A, Hemeg HA (2017) Application of MALDI-TOF MS fingerprinting as a quick tool for identification and clustering of foodborne pathogens isolated from food products. New Microbiol 40: 269-278. ISN 1121-7138

Fairfax MR, Lephart PR, Salimnia H (2014) Weissella confusa: problems with identification of an opportunistic pathogen that has been found in fermented foods and proposed as a probiotic. Front Microbiol 5: 254. https://doi.org/10.3389/fmicb.2014.00254

Fernández-No IC, Böhme K, Gallardo JM, Barros-Velázquez J, Cañas B, Calo-Mata P (2010) Differential characterization of biogenic amine-producing bacteria involved in food poisoning using MALDI-TOF mass fingerprinting. Electrophoresis 31: 1116-1127. https:// doi.org/10.1002/elps.200900591

Kern CC, Vogel RF, Behr J (2014) Differentiation of Lactobacillus brevis strains using Matrix-Assisted-Laser-Desorption/IonizationTime-of-Flight Mass Spectrometry with respect to their beer spoilage potential. Food Microbiol 40: 18-24. https://doi.org/10.1016/j. fm.2013.11.015

Kołożyn-Krajewska D (1995) Microorganisms in food - threats or benefits. Zywność Technologia Jakość 3: 21-31 (in Polish)

Kosikowska U, Stępień-Pyśniak D, Pietras-Ożga D, Andrzejczuk S, Juda M, Malm A (2015) Application of MALDI-TOF MS for identification of clinical isolates from humans and animals. Diagn Lab 51: 23-30 (in Polish)

Król A, Pomastowski P, Rafińska K, Railean-Plugaru V, Walczak J, Buszewski B (2018) Microbiology neutralization of zearalenone using Lactococcus lactis and Bifidobacterium sp. Anal Bioanal Chem 410: 943-952. https://doi.org/10.1007/s00216-017-0555-8

Lee M-R, Tsai C-J, Hsueh P-R (2015) Identification of Weissella species by matrix-assisted laser desorption/ionization time-of-flight mass spectrometry. Front Microbiol 6: 1246. https://doi.org/10.3389/ fmicb.2015.01246

Lévesque S, Dufresne PJ, Soualhine H, Domingo M-C, Bekal S, Lefebvre B, Tremblay C (2015) A side by side comparison of bruker biotyper and VITEK MS: utility of MALDI-TOF MS technology for microorganism identification in a public health reference laboratory. PLoS One 10: e0144878. https://doi.org/10.1371/journal. pone. 0144878

Lo CI, Fall B, Sambe-Ba B, Flaudrops C, Faye N, Mediannikov O, Sokhna C, Wade B, Raoult D, Fenollar F (2017) Value of matrix assisted laser desorption ionization-time of fight (MALDI-TOF) mass spectrometry in clinical microbiology and infectious diseases in Africa and tropical areas. Afr J Microbiol Res 11: 1360-1370. https://doi. org/10.5897/AJMR2016.8181

Mazari W, El Haci IA, Boucherit Otmani Z (2017) Control of fungal biofilm formation in dental environment. In Antimicrobial research: Novel bioknowledge and educational programs. Méndez-Vilas A ed, pp 315-323. Chapter: Biofilms. Publisher: FORMATEX-SPAIN

Moothoo-Padayachie A, Kandappa HR, Krishna SBN, Maier T, Govender P (2013) Biotyping Saccharomyces cerevisiae strains using matrix-assisted laser desorption/ionization time-of-flight mass spectrometry (MALDI-TOF MS). Eur Food Res Technol 236: 351-364. https://doi.org/10.1007/s00217-012-1898-1

Nicolaou N, Xu Y, Goodacre R (2012) Detection and quantification of bacterial spoilage meat using MALDI-TOF-MS and multivariate analysis. Anal Chem 84: 5951-5958. https://doi.org/10.1021/ ac $300582 \mathrm{~d}$
Nomura F (2015) Proteome-based bacterial identification using matrix-assisted laser desorption ionization-time of flight mass spectrometry (MALDI-TOF MS): A revolutionary shift in clinical diagnostic microbiology. Biochim Biophys Acta 1854: 528-537. https://doi. org/10.1016/j.bbapap.2014.10.022

Ouedraogo R, Daumas A, Capo C, Mege J-L, Textoris J (2013) Wholecell MALDI-TOF mass spectrometry is an accurate and rapid method to analyze different modes of macrophage activation. $J V$ is Exp 82: 50926. https://doi.org/10.3791/50926

Pavlovic M, Huber I, Konrad R, Busch U (2013) Application of MALDI-TOF MS for the identification of food borne bacteria. Open $\mathrm{Mi}$ crobiol J 15: 135-141. https://doi.org/10.2174/1874285801307010135

Pomastowski P, Złoch M, Rodzik A, Ligor M, Kostrzewa M, Buszewski B (2019) Analysis of bacteria asscociated with honeys of different geographical and botanical origin using two different identification approaches: MALDI-TOF MS and $16 \mathrm{~S}$ rDNA PCR technique. PLoS One 14: e0217078. https://doi.org/10.1371/journal. pone.0217078

Quéro L, Girard V, Pawtowski A, Tréguer S, Weill A, Arend S, Cellière B, Polsinelli S, Monnin V, van Belkum A, Vasseur V, Nodet P, Mounier J (2018) Development and application of MALDI-TOF MS for identification of food spoilage fungi. Food Microbiol 81: 7688. https://doi.org/10.1016/j.fm.2018.05.001

Quintela-Baluja M, Böhme K, Fernández-No IC, Morandi, S, Alnakip ME, CaamañoAntelo S, Barros-Velázquez J, Calo-Mata P (2013) Characterization of different food-isolated Enterococcus strains by MALDI-TOF mass fingerprinting. Electrophoresis 34: 2240-2250. https://doi.org/10.1002/elps.201200699

Sánchez-Juanes F, Teixeira-Martín V, González-Buitrago JM, Velázquez E, Flores-Félix JD (2020) Identification of species and subspeciesof lactic acid bacteria present in spanish cheeses type "Torta" by MALDI-TOF MS and pheS gene analyses. Microorganisms 8: 301. https://doi.org/10.3390/microorganisms8020301

Singhal N, Kumar M, Kanaujia PK, Virdi JS (2015) MALDI-TOF mass spectrometry: an emerging technology for microbial identification and diagnosis. Front Microbiol 6: 791. https://doi.org/10.3389/ fmicb.2015.00791

Soro-Yao AA, Schumann P, Thonart P, Djè KM, Pukall R (2014) The use of MALDI-TOF mass spectrometry, ribotyping and phenotypic tests to identify lactic acid bacteria from fermented cereal foods in Abidjan (Côte d'Ivoire). Open Microbiol J 8: 78-86. https://doi. org/10.2174/1874285801408010078

Stephan R, Ziegler D, Pflüger V, Vogel G, Lehner A (2010) Rapid genus- and species-specific identification of cronobacter spp. by matrix-assisted laser desorption ionization-time of flight mass spectrometry. J Clin Microbiol 48: 2846-2851. https://doi.org/10.1128/ JCM.00156-10

Szczepańska E, Robak M (2013) Proteomika w badaniu drobnoustrojów. Acta Sci Pol Biotechnologia 12: 25-40. doi: 10.13140/2.1.4079.6803

Ulrich S, Gottschalk C, Dietrich R, Märtlbauer E, Gareis M (2019) Identification of cereulide producing Bacillus cereus by MALDI-TOF MS. Food Microbiol 82: 75-81. https://doi.org/10.1016/j. fm.2019.01.012.

Usbeck JC, Kern CC, Vogel RF, Behr J (2013) Optimization of experimental and modelling parameters for the differentiation of beverage spoiling yeasts by Matrix-Assisted-Laser-Desorption/IonizationTime-of-Flight Mass Spectrometry (MALDI-TOF MS) in response to varying growth conditions. Food Microbiol 36: 379-387. https:// doi.org/10.1016/j.fm.2013.07.004

Vranakis I, Chochlakis D, Sandalakis V, Tselentis Y, Psaroulaki A (2012) Cost- and time-effectiveness of application of MALDI-TOF mass spectrometry methodology in a food and water microbiology laboratory. Arch Hellenic Med 29: 477-479

Welker M, Moore ERB (2011) Applications of whole-cell matrix laser-desorption/ionization time-of-flight mass spectrometry in systematic microbiology. Syst Appl Microbiol 34: 2-11. https://doi. org/10.1016/j.syapm.2010.11.013. 